\title{
Efficiently enforcing artisanal fisheries to protect estuarine biodiversity
}

\author{
Micheli Duarte de Paula Costa (iD) $1,2,8$ Morena Mills (iD) ${ }^{1,3}$ Anthony J. Richardson (iD 4,5 Richard A. Fuller (iD 1 \\ José H. Muelbert id , ${ }^{2,6}$ and Hugh P. Possingham (iD 1,7 \\ ${ }^{1}$ School of Biological Sciences, The University of Queensland, St. Lucia, Brisbane, Queensland 4072 Australia \\ ${ }^{2}$ Laboratório de Ecologia do Ictioplâncton, Instituto de Oceanografia, Universidade Federal do Rio Grande, Campus Carreiros, Avenida Itália \\ Km 8, CP 474, Rio Grande, RS 96203900 Brazil \\ ${ }^{3}$ Department of Life Sciences, Imperial College London, Silwood Park Campus, Ascot SL5 7PY United Kingdom \\ ${ }^{4}$ Commonwealth Scientific and Industrial Research Organization (CSIRO) Oceans and Atmosphere, Queensland BioSciences Precinct (QBP), \\ St. Lucia, Queensland 4072 Australia \\ ${ }^{5}$ School of Mathematics and Physics, University of Queensland, St. Lucia, Queensland 4072 Australia \\ ${ }^{6}$ Institute for Marine and Antarctic Studies, University of Tasmania, Hobart, Tasmania Australia \\ ${ }^{7}$ The Nature Conservancy, South Brisbane, Queensland 4101 Australia
}

\begin{abstract}
Artisanal fisheries support millions of livelihoods worldwide, yet ineffective enforcement can allow for continued environmental degradation due to overexploitation. Here, we use spatial planning to design an enforcement strategy for a pre-existing spatial closure for artisanal fisheries considering climate variability, existing seasonal fishing closures, representative conservation targets and enforcement costs. We calculated enforcement cost in three ways, based on different assumptions about who could be responsible for monitoring the fishery. We applied this approach in the Patos Lagoon estuary (Brazil), where we found three important results. First, spatial priorities for enforcement were similar under different climate scenarios. Second, we found that the cost and percentage of area enforced varied among scenarios tested by the conservation planning analysis, with only a modest increase in budget needed to incorporate climate variability. Third, we found that spatial priorities for enforcement depend on whether enforcement is carried out by a central authority or by the community itself. Here, we demonstrated a method that can be used to efficiently design enforcement plans, resulting in the conservation of biodiversity and estuarine resources. Also, cost of enforcement can be potentially reduced when fishers are empowered to enforce management within their fishing grounds.
\end{abstract}

Key words: artisanal fisheries; climate variability; enforcement; ENSO events; estuaries; marine spatial planning; seasonal closures.

\section{INTRODUCTION}

Coastal lagoons and estuaries are among the most productive ecosystems in the world, providing a range of ecosystem services and aquatic resources. Estuaries act as nurseries, feeding, and breeding areas for a wide variety of animals including those of economic importance (Babler 2000). Conservation in estuaries is particularly challenging due to conflicts among diverse sectors dependent on the ecosystem. Yet because of their proximity to human populations, coastal and marine ecosystems have often been degraded, leading to habitat degradation, species loss and fisheries overexploitation (Sumaila et al. 2011, Arthington et al. 2016). Artisanal fisheries are an important economic activity in estuaries, supporting the livelihoods of many people around the world. This activity has low operating costs, small boats, few fishers per boat, and limited profit (Kurien and Willmann 2009). In Brazil, artisanal fisheries are data poor (Kaliloski and Vasconcellos 2012) even though $>50 \%$ of fishery production comes from this sector (Vasconcellos et al. 2007). This makes it difficult to identify and evaluate the effectiveness of management actions (e.g., enforcement, patrolling, or policies) to conserve estuarine biodiversity.

Manuscript received 2 January 2018; accepted 10 April 2018. Corresponding Editor: Eric Ward.

${ }^{8}$ E-mail: m.duartedepaulacost@uq.edu.au
To date, most Brazilian fisheries management has focused on controls of catch, effort and technical regulations such as restrictions on mesh size, closed seasons, and areas. Enforcement typically encompasses patrols to detect and prosecute illegal activities (Anderson 1989), which is expensive and in practice often concentrated in areas with easy access from the places where patrols are stationed (Plumptre et al. 2014). Given limited resources for enforcement, there is scope to strategically allocate resources in space and time to increase the probability that enforcement reduces the amount of poaching. Until now, fisheries enforcement and spatial conservation planning have tended to be separate, but it might be possible to use ideas from conservation planning to optimize enforcement, and thus, protect biodiversity at a minimum cost. Conservation planning encompasses the spatial allocation of conservation actions, based on the distribution of conservation targets and the costs of those actions (Kukkala and Moilanen 2013). If we consider that the main objective of fisheries enforcement is to protect commercially valuable species, we can combine fisheries data with conservation planning to optimize the design of enforcement strategies. Despite some studies considering the optimization of enforcement in other systems (Ban et al. 2009, Plumptre et al. 2014, Davis et al. 2015, Arias et al. 2016, Dhanjal-Adams et al. 2016), we are still lacking a spatial prioritization approach for fisheries enforcement that includes variability in fish abundance (often driven by a variable climate) and fishing effort. 
We applied our approach to the Patos Lagoon estuary (PLE, Brazil), which borders a national protected area established in the wetlands surrounding the Patos-Mirim lagoon system on the Brazilian coastline (Odebrecht et al. 2010). Unlike many estuaries in the world, the PLE is located in a micro-tidal region, with estuarine dynamics controlled mainly by wind and precipitation (Odebrecht et al. 2010). Species composition, abundance and biomass vary in space and time within the PLE in response to changes in salinity and temperature, which are in turn affected by climatic conditions (Odebrecht et al. 2010). Periods of peak freshwater discharge are associated with El Niño episodes when rainfall significantly increases, while La Niña events are associated with drought conditions (Odebrecht et al. 2010). Due to the influence on salinity, these events affect the distribution of several marine and freshwater species, and consequently, the fisheries production in the estuary (Odebrecht et al. 2010). Incorporating fish distribution into an enforcement plan can contribute to better allocation of law enforcement effort and consequently protect overexploited target species and their habitats.

Here, we investigate whether the spatial priorities for enforcement change seasonally and/or with respect to El Niño Southern Oscillation (ENSO) variability, and how this is affected by shifting enforcement responsibility from government to local communities. We used spatial planning tools to design an enforcement strategy for a pre-existing management plan for estuarine artisanal fisheries through time and space, considering temporal variation in ENSO.

\section{Materials And Methods}

\section{The artisanal fishery at the PLE}

The PLE (Appendix S1) and adjacent shelf are among the most important fishing grounds along the Brazilian coast (Haimovici 1997). There is artisanal fishing throughout the estuary, but it is concentrated in areas close to fishing communities (Reis and D'Incao 2000), and supports at least 2,000 fishers (Kaliloski and Vasconcellos 2012). Trawl nets, gillnets, and fyke nets are the main gears used in the estuary. Artisanal fishery production varies from $\sim \mathrm{R} \$ 23$ million to $\mathrm{R} \$ 46$ million (Brazilian Reais) per year (i.e., \$US7 million to \$US13 million) in a good fishing season (Kaliloski and Vasconcellos 2012). Most target species are marine and use the estuary to complete their life cycle: for example, the pink shrimp Penaeus paulensis and the whitemouth croaker Micropogonias furnieri migrate from the estuary to the ocean to spawn (Odebrecht et al. 2010). Early life stages of these species recruit to the PLE where they find suitable conditions for fast growth, and protection against currents and predators in the submerged Ruppia maritima meadows (Garcia and Vieira 1997, Costa et al. 2014, Ruas et al. 2014). By contrast, the sea catfish Genidens barbus enters the estuary in August and September to complete maturation, and spawns in November and December. After that, females return to the sea and males, which are mouth-breeders, keep carrying their eggs until January and February (Haimovici and Cardoso 2016). Since the 1980s, there has been a decline in landings for all main target resources due to excessive fishing effort, catches at inappropriate stages of their life cycle, pollution, and illegal fishing (Haimovici 1997, Reis and D'Incao 2000, Odebrecht et al. 2010, Kaliloski and Vasconcellos 2012, Haimovici and Cardoso 2016).

Seasonal fishing closure, gear restrictions, minimum size, licenses, spatial restrictions, and protection of spawning grounds are the main fisheries management tools used in the PLE to manage the artisanal fishery (Haimovici and Cardoso 2016). However, they are poorly enforced. According to the Brazilian fishery legislation, fishing for shrimp, mullet, croaker, and catfish in the PLE is forbidden during several months of the year, although the majority of fishers continue to catch these species throughout the year (Kaliloski and Vasconcellos 2012). See Appendix S2 for further information about the study area.

\section{Spatial prioritization approach}

We used the decision support tool Marxan (Ball et al. 2009) with a probabilistic spatial prioritization approach to determine an enforcement strategy for artisanal fisheries at the PLE through time and space. Marxan uses a simulated annealing algorithm to find alternative good solutions to create minimum cost reserves (Ball et al. 2009). Marxan with probability is a modified version of Marxan that minimizes the cost of selected planning units, subject to the achievement of conservation targets with an acceptably low risk (Game et al. 2008). We aimed to protect $25 \%$ of each of our main species considered in the seasonal fishing closure and $10 \%$ of the remaining estuarine biodiversity for each scenario tested. Our targets were set following the Aichi Biodiversity Targets (Convention on Biological Diversity 2013), which aims to protect at least $10 \%$ of coastal and marine areas by 2020. As our target species are currently overexploited they were given a higher target to increase the chance of recovery of the population.

TABLE 1. Details for each climate groups (scenarios), costs, and seasonal fishing closure design implemented in the spatial prioritization for enforcement using Marxan with Probability. Here, we analysed three different cost layers and four seasonal fishing targets for each climate scenario.

\begin{tabular}{|c|c|c|}
\hline Climate groups (scenarios) & Costs & Seasonal fishing closure design \\
\hline 1. Ignoring climate variability & enforcement & $\begin{array}{l}\text { Autumn: whitemouth croaker }(25 \%) \text { and other conservation } \\
\text { features }(10 \%)\end{array}$ \\
\hline $\begin{array}{l}\text { 2. Considering climate variability (seasonal } \\
\text { scenarios for each ENSO intensity) }\end{array}$ & $\begin{array}{l}\text { enforcement by } \\
\text { fishers }\end{array}$ & $\begin{array}{l}\text { Winter: whitemouth croaker }(25 \%) \text {, catfish }(25 \%) \text {, pink shrimp } \\
(25 \%) \text {, and other conservation features }(10 \%)\end{array}$ \\
\hline \multirow[t]{2}{*}{$\begin{array}{l}\text { 3. Considering climate variability as } \\
\text { conservation features (seasonal scenarios) }\end{array}$} & $\begin{array}{l}\text { distance from fishing } \\
\text { colony }\end{array}$ & $\begin{array}{l}\text { Spring: whitemouth croaker }(25 \%) \text {, catfish }(25 \%) \text {, pink shrimp } \\
(25 \%) \text {, and other conservation features }(10 \%)\end{array}$ \\
\hline & & Summer: pink shrimp $(25 \%)$ and other conservation features $(10 \%)$ \\
\hline
\end{tabular}


In this prioritization approach, we used information about the probability a planning unit contains suitable habitats for our three target species (whitemouth croaker, pink shrimp, and catfish). The Marxan with probabilities software selects enough planning units so that the species that does not meet its target is acceptably low. To implement this approach, we required data about the probability that each planning unit is within their suitable habitats. For that, we used the probabilistic output from our MaxEnt distribution models (software version 3.3; Appendix S2) to estimate this probability. MaxEnt is a species distribution modelling tool that uses presence-only data to predict the distribution of a species based on environmental variables (Phillips and Dudik 2008).

As our objective is to minimize the chance that the selected planning units are not suitable for the occurrence of our target species in addition to minimize the cost of enforcement, we estimated our habitat suitability probability (HS) as

$$
\mathrm{HS}=1-P
$$

where $P$ is the probability of occurrence derived from our Maxent outputs.

To prioritize enforcement spatially during seasonal fishing closures at the PLE, we used Marxan with probability to evaluate three alternative climate scenario groups, which varied based on whether they considered climate variability and on their associated management complexity (see
Table 1). Every group of scenarios included prioritizations for enforcement within different seasons. Group 1 scenarios ignored climate variability (i.e., ignoring ENSO). Group 2 scenarios considered climate variability (i.e., varying intensities of ENSO: weak, moderate, and very strong events); so, there was an enforcement prioritization for every season and every ENSO intensity (20 scenarios in total). Group 3 scenarios considered climate variability (i.e., species distributions layers for each ENSO intensity) as conservation features, so similar to Group 1 there was only one scenario per season but the variation in the distribution of fish associated with different ENSO intensities was captured. Groups 1 and 3 scenarios represent a simpler approach to manage enforcement (four prioritizations) when compared to Group 2 scenarios (20 prioritizations). For each scenario, Marxan with probability was calibrated and all scenarios were run with 100 repetitions and 1,000,000 iterations. We decided to not spatially cluster the selected sites to ensure that we achieved the most cost-efficient solutions. In addition, we set the target probability as $90 \%$, which means the selected sites have a $90 \%$ chance of meeting the selected target.

\section{Expected benefit of enforcement}

Even though the temporal closure was designed specifically to protect the pink shrimp, catfish, mullet, and
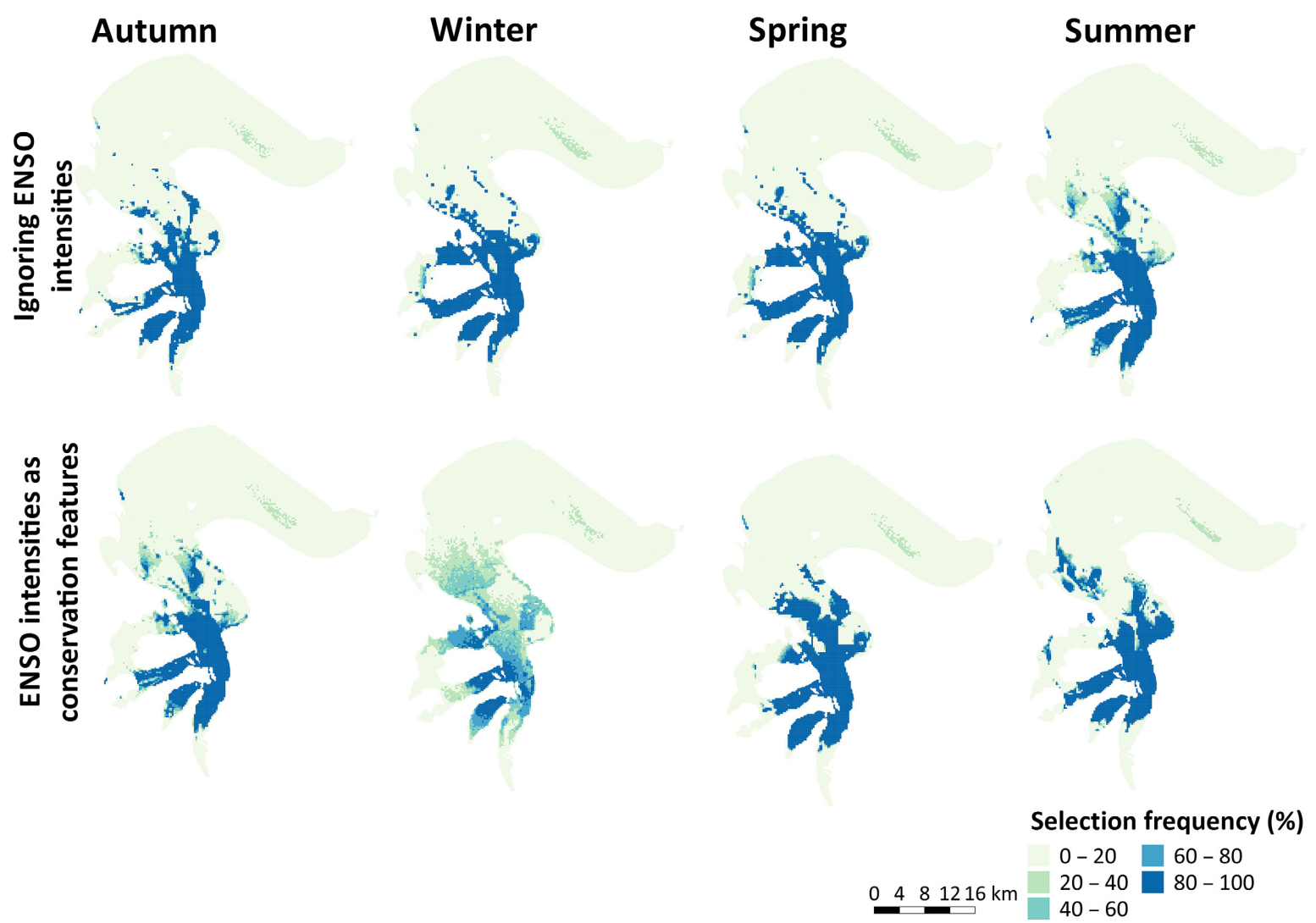

FIG. 1. Spatial priorities for enforcement of artisanal fisheries in the Patos Lagoon estuary when ignoring El Niño Southern Oscillation (ENSO) intensities (Group 1) and when incorporating spatial distribution of species during distinct ENSO intensities as conservation features (Group 3). Selection frequency is how often a planning unit is selected across 100 runs under each scenario. Here, the cost layer used was the estimated enforcement cost by the government. 
whitemouth croaker, our spatial planning approach has two objectives: to spatially prioritize enforcement, and to maximize biodiversity protection while minimizing enforcement costs. In this sense, we considered 38 estuarine species as a surrogate for biodiversity across the estuary, including the three species regulated by the seasonal closure legislation (pink shrimp, catfish, and whitemouth croaker). We also included key biophysical features including bathymetry, sediment type, and submerged aquatic vegetation. In total, 64 conservation features were considered (details on the specific target used for each feature are listed on Table 1). Our expected benefit is a proxy for the biomass left in the system that otherwise would be removed by the artisanal fishery, and it was estimated as the value of a conservation feature in a planning unit multiplied by an estimated fishing effort. We estimated fishing effort based on the human population and distance from each fishing colony (Kaliloski and Vasconcellos 2012), as fishers tend to fish closer to their colonies (Freitas and Tagliani 2009, Kaliloski and Vasconcellos 2012).

\section{Expected cost of enforcement}

We analysed these scenarios using three different cost layers: (1) enforcement cost, (2) enforcement cost by engaging with fishers, and (3) distance from fishing colonies (Table 1). Our approach to calculating the cost of enforcement $\left(C_{\mathrm{e}}\right)$ was based on Dhanjal-Adams et al. (2016). The enforcement cost was proportional to the number of rangers $(N)$, monthly salary $(S)$, staff on-cost $(25 \%$, Ban et al. 2009), the time spent enforcing each planning unit $(E)$, the price per kilometer of travel, and the distance in kilometers to each planning unit $(D)$. We estimated the maximum possible hourly salary for a ranger at R\$33.53 (MTFCGU 2016). We also assumed that three rangers always patrolled the PLE for $5 \mathrm{~h}$ per day. We estimated the price per kilometer of travel $(P)$ as $\mathrm{R} \$ 1.67$ based on 2.5-L engine and fuel costs. Then, assuming that patrolling always starts from the Regional Environmental Agency, we estimated its distance $(D)$ to each planning unit. Our enforcement cost was estimated to be

$$
C_{\mathrm{e}}=1.25 N S E+P D
$$

for a planning unit. We also considered a more communitybased scenario, where fishers are empowered by the government to enforce management within their fishing grounds. The Brazilian government already pays a fishing insurance (minimum national wage) for artisanal fishers when fishing is closed to four species in the PLE. To estimate this cost layer, we modified the first equation by excluding the number of rangers and staff on-costs. We assumed that the salary is the hourly rate of the minimum national wage. This cost layer represents the cost of seven fishers (e.g., one from each fishing colony considered in this study) engaging in a comanagement of estuarine resources. In this scenario, fishers are responsible for patrolling, capturing the benefits of management, and minimizing illegal activities during the fishing closure. Our third cost layer was estimated using the distance of each planning unit to the nearest fishing colony.

We compared our selection frequency results for two climate scenarios groups: seasonal scenarios without ENSO and seasonal scenarios with varying intensities of ENSO. We used the Pearson correlation coefficient $(\rho)$ to test the similarity between the selection frequency results. A high correlation indicates similar spatial priorities for enforcement. We only considered the correlation coefficients when comparing our results, as these are unaffected by spatial autocorrelation (Nhancale and Smith 2011).

\section{RESULTS}

Spatial priorities for enforcement were similar across ENSO intensities (Fig. 1, Appendix S3: Fig. S2 to S5; $\rho>0.70$; Table 2), although there were differences in cost and the amount of area selected for enforcement (Fig. 2). For example, during El Niño events we would need to enforce an average of $628 \mathrm{~km}^{2}$ at an average total cost of $\mathrm{R} \$ 141,000$ while, during La Niña years, we would need to enforce an average of $615 \mathrm{~km}^{2}$ at an average total cost of $\mathrm{R} \$ 129,200$ based on Group 2 scenarios (Fig. 2). Enforcement scenarios ignoring climate variability (Group 1) had a relatively higher

TABle 2. Pearson correlation coefficients $(\rho)$ applied to test the similarity between the selection frequency results for each group of scenarios.

\begin{tabular}{|c|c|c|c|c|}
\hline \multirow[b]{2}{*}{ Scenario 1} & \multicolumn{4}{|c|}{ Scenario 2} \\
\hline & Winter & Spring & Summer & $\overline{\text { Autumn }}$ \\
\hline \multicolumn{5}{|l|}{ El Niño } \\
\hline \multicolumn{5}{|l|}{ (a) Weak } \\
\hline Winter & 0.81 & & & \\
\hline Spring & & 0.83 & & \\
\hline Summer & & & 0.79 & \\
\hline Autumn & & & & 0.81 \\
\hline \multicolumn{5}{|l|}{ (b) Moderate } \\
\hline Winter & 0.78 & & & \\
\hline Spring & & 0.84 & & \\
\hline Summer & & & 0.82 & \\
\hline Autumn & & & & 0.81 \\
\hline \multicolumn{5}{|l|}{ (c) Very strong } \\
\hline Winter & 0.81 & & & \\
\hline Spring & & 0.88 & & \\
\hline Summer & & & 0.83 & \\
\hline Autumn & & & & 0.84 \\
\hline \multicolumn{5}{|l|}{ La Niña } \\
\hline \multicolumn{5}{|l|}{ (a) Weak } \\
\hline Winter & 0.74 & & & \\
\hline Spring & & 0.81 & & \\
\hline Summer & & & 0.77 & \\
\hline Autumn & & & & 0.77 \\
\hline \multicolumn{5}{|l|}{ (b) Moderate } \\
\hline Winter & 0.85 & & & \\
\hline Spring & & 0.80 & & \\
\hline Summer & & & 0.77 & \\
\hline Autumn & & & & 0.80 \\
\hline \multicolumn{5}{|l|}{ Scenario 3} \\
\hline Winter & 0.77 & & & \\
\hline Spring & & 0.74 & & \\
\hline Summer & & & 0.74 & \\
\hline Autumn & & & & 0.80 \\
\hline
\end{tabular}

Note: All results were significant at the level of $P<0.001$. 
average total cost and area, $\mathrm{R} \$ 156,000$ and $650 \mathrm{~km}^{2}$ respectively, when compared to ENSO scenarios from Group 2.

Enforcement was more expensive in winter because particular sites would always be selected for enforcement (i.e., they were irreplaceable), while in spring larger areas needed to be protected because fish distributions were larger. Scenarios considering climate variability as conservation features (i.e., in an integrated manner, Group 3) were more expensive (average cost $=\mathrm{R} \$ 187,800)$ than scenarios ignoring climate variability (Group 1), however it enforced a larger area $\left(694 \mathrm{~km}^{2}\right)$. While scenarios ignoring climate variability (Group 1) are cheaper than scenarios including climate variability as conservation features (Group 3); by increasing our enforcement budget by $20 \%$ (R $\$ 10,000 /$ month) we can incorporate climate variability into the enforcement plan. This could lead to an increase of more than $40 \mathrm{~km}^{2}$ in the mean area enforced (Fig. 2). In general, areas in the main channel and in shallow waters close to the estuarine shore were the most important for protection and enforcement regardless of the season, because these were cheaper to patrol and important for biodiversity.

Empowering fishers to enforce their own fishing ground emerged as the most efficient strategy for an enforcement plan at PLE. Spatial priorities differed with changes in responsibility for the enforcement (Fig. 3, Appendix S3). In this case, mean cost decreased by $47 \%$ and $55 \%$ when fishers were empowered to monitor their own fishing ground in the scenario ignoring climate variability (Group 1) and scenarios considering climate variability as conservation features (Group 3), respectively (Fig. 2). The mean area patrolled was also increased, since more area could be considered in the enforcement plan (Figs. 2 and 3 ) for less money.

\section{Discussion}

In this paper, we provided an example of how spatial prioritization can be used to design enforcement plans, using Patos Lagoon estuary as an example. In our case study, we designed an enforcement strategy for a pre-existing spatial closure for artisanal fisheries considering climate variability, existing seasonal fishing closures, representative conservation targets, and enforcement costs.

Law enforcement is needed to reduce illegal activities such as non-compliance with marine protected areas, seasonal closures, and restrictions on gear and size (Game et al. 2009, Edgar et al. 2014). In this context, the approach we
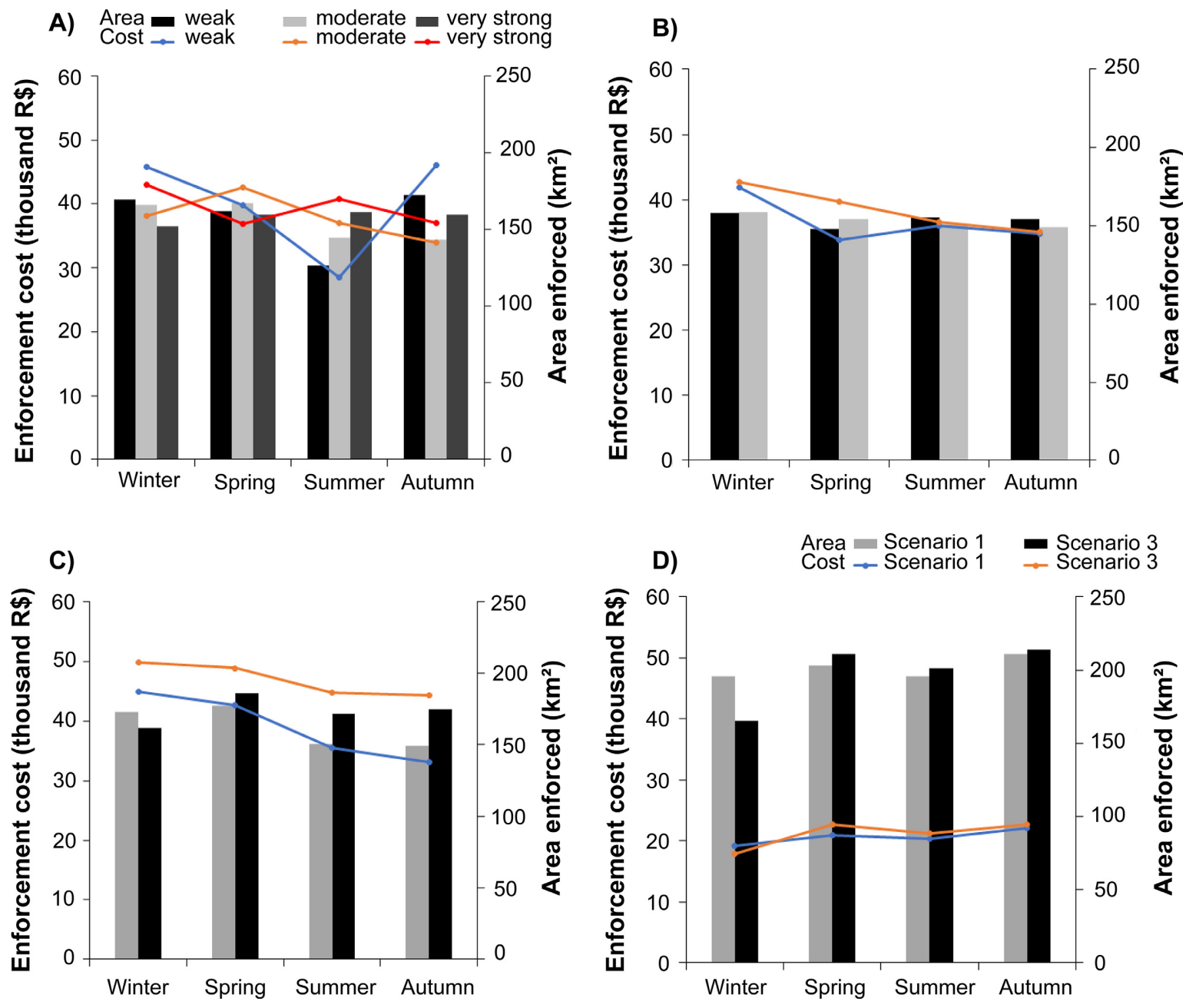

FIG. 2. Cost and area selected to enforce the artisanal fishery in the Patos Lagoon estuary. Results displayed in this graph represent scenarios from Group 1, 2 and 3: (A) El Niño and (B) La Niña, (C) enforcement by environmental agency, and (D) enforcement by fishers. 
demonstrated here is timely considering the current concerns around illegal fishing. While there has been prioritizations for enforcement (Ban et al. 2009, Plumptre et al. 2014, Davis et al. 2015, Arias et al. 2016, Dhanjal-Adams et al. 2016), none considered variation through time. We found that spatial priorities for enforcement varied markedly among seasons, indicating that temporally dynamic enforcement is needed in this system. In contrast, and somewhat unexpectedly, priorities did not change substantially for different climate scenarios. We also found that spatial priorities changed based on who is responsible for patrols, suggesting that cost of enforcement is reduced when fishers themselves enforce their fishing grounds. Marine protected areas that are well enforced, were developed with fishers participation, and that promote sustainable fishing were found to have healthier fish stocks and fishers with higher income compared to those that did not (Di Franco et al. 2016). We could expect the same benefits for a well-enforced seasonal closure.

\section{Considering climate variability to enforce the seasonal closures in the PLE}

Artisanal fishing in the PLE is only one of multiple activities that can impact the ecological health of the estuarine ecosystem. Previous studies in this estuary show that climate change is already having an impact, decreasing the productivity, and consequently, reducing fisheries stock (Odebrecht et al. 2010,
Haimovici and Cardoso 2016). One expected impact of climate change in southern Brazil is an increase in frequency and intensity of extreme events such as ENSOs (PBMC 2014). Thus, conservation plans (i.e., enforcement or the design of marine protected areas) could consider climate variability.

While fishing is prohibited in the PLE during the seasonal closure, a high percentage of fishers declare that they usually fish during the closure (Kaliloski and Vasconcellos 2012). A seasonal enforcement plan can be a cost-effective solution (i.e., better outcomes achieved given the amount of resources spent) to decrease illegal fishing in the PLE, where temporal variation plays an important role in determining fish distribution. We found that it is possible to optimize enforcement for the pre-existing seasonal closure. However, it is important to highlight that other forms of management that are in place (e.g., gear restrictions, minimum sizes, licenses, etc.) will still need spatial plans to be efficiently enforced.

In the PLE, most of the fisheries collapsed as long ago as the 1980s due to overexploitation (Haimovici and Cardoso 2016). For example, the abundance of whitemouth croaker and the age of older fishes in the catch have been decreasing for decades (Haimovici and Cardoso 2016). In addition to the fisheries that target this species, the fyke nets used to caught pink shrimp also capture a large number of juveniles of fish (Vieira et al. 1996). Many countries lack the resources for fisheries management, resulting in a total or partial fish stock collapse around the world (Anderson
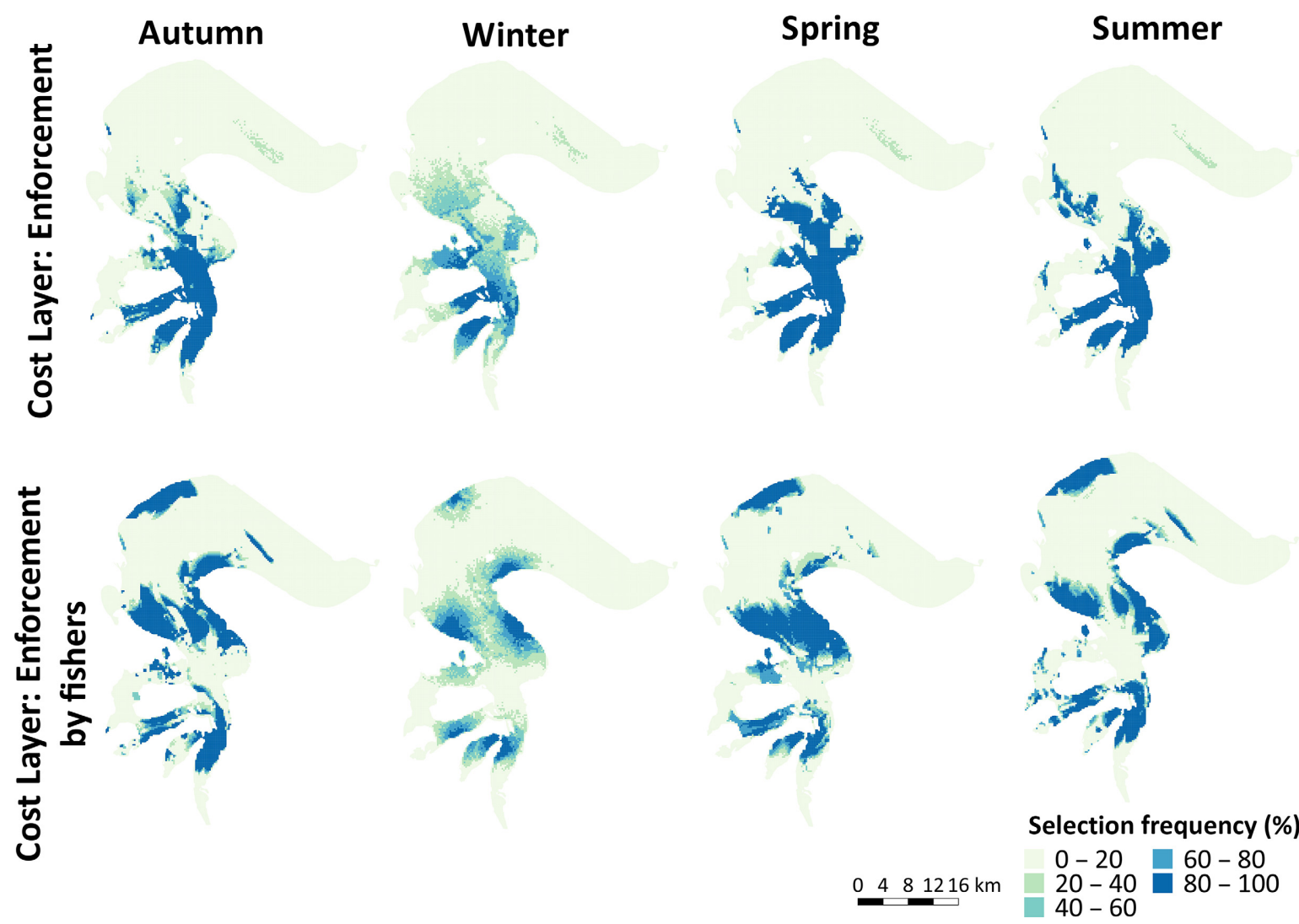

FIG. 3. Spatial priorities for enforcement of artisanal fisheries in the Patos Lagoon estuary when incorporating spatial distribution of species in distinct ENSO intensities as conservation features (Group 3). Selection frequency is how often a planning unit is selected across 100 runs under each scenario. Here, the cost layers used were the estimated enforcement cost by the environmental agency, and the opportunity cost using the distance from the fishing colonies as a proxy for enforcement cost by fishers. 
1989, Pomeroy and Berkes 1997, Agnew et al. 2009, Arias et al. 2016, Arthington et al. 2016) and in Brazil (Reis and D'Incao 2000, Kaliloski and Vasconcellos 2012).

A potential enforcement plan for the PLE, where federal environmental agencies work together with artisanal fishers to effectively enforce and protect estuarine resources and biodiversity can be represented by Group 3 (scenarios including climate variability as conservation features; Fig. 4). It has been proposed that co-management can increase the efficiency of fisheries management (Pomeroy and Berkes 1997) and enhance fishers perception of conservation (Gelcich et al. 2008). Fisheries co-management has already been considered by managers in the PLE, with the creation of the Forum of Patos Lagoon in 1996 (Reis and Rodrigues 2003). However, the sharing of responsibilities between the government and fishing communities in the PLE has not yet been considered (Kaliloski and Vasconcellos 2012). Here, we showed that empowering fishers to enforce their own fishing grounds in a community-based management is a potential cost-effective strategy to reduce law enforcement costs and increase the sustainability of estuarine resources and biodiversity.

\section{Challenges for spatial prioritization for enforcement}

Our approach for spatially prioritizing enforcement can be used to design fisheries enforcement plans and modified to address different enforcement needs. We acknowledge that prioritizing enforcement represents a substantial practical challenge, which ideally uses spatial data on poaching and better estimates the cost of enforcement. For example, our case study did not account for the actual behavior of illegal fishers or any existing spatial patterns of illegal fishing, such as areas of high prevalence of illegal fishing and/or infractions. Unfortunately, there is no such data available for Patos Lagoon estuary. However, as artisanal fishers in the Patos Lagoon estuary generally operate close to their colonies and are loyal to their fishing grounds (Freitas and Tagliani 2009, Kaliloski and Vasconcellos 2012), we believe that our estimates of the spatial pattern is not unrealistic.

We believe that incorporating these data on species abundance and/or the distribution of each type of fishing gear in the estuary into spatial planning may improve the design of the enforcement plan, and better estimate the associated benefits. A previous study in Chile (Davis et al. 2015) assessed the impact of enforcement of marine protected areas on species abundance and found that the revenue for fishers increased with enforcement; economic benefits were greater than enforcement costs where poaching is prevented.

In conclusion, we demonstrated an approach that can be useful to managers from data-poor regions by offering a way to prioritize which areas could be included in an enforcement strategy. However, in cases where managers have spatial data on patterns of illegal fishing and real data on costs of enforcement, we do recommend that these layers are incorporated into the plan.

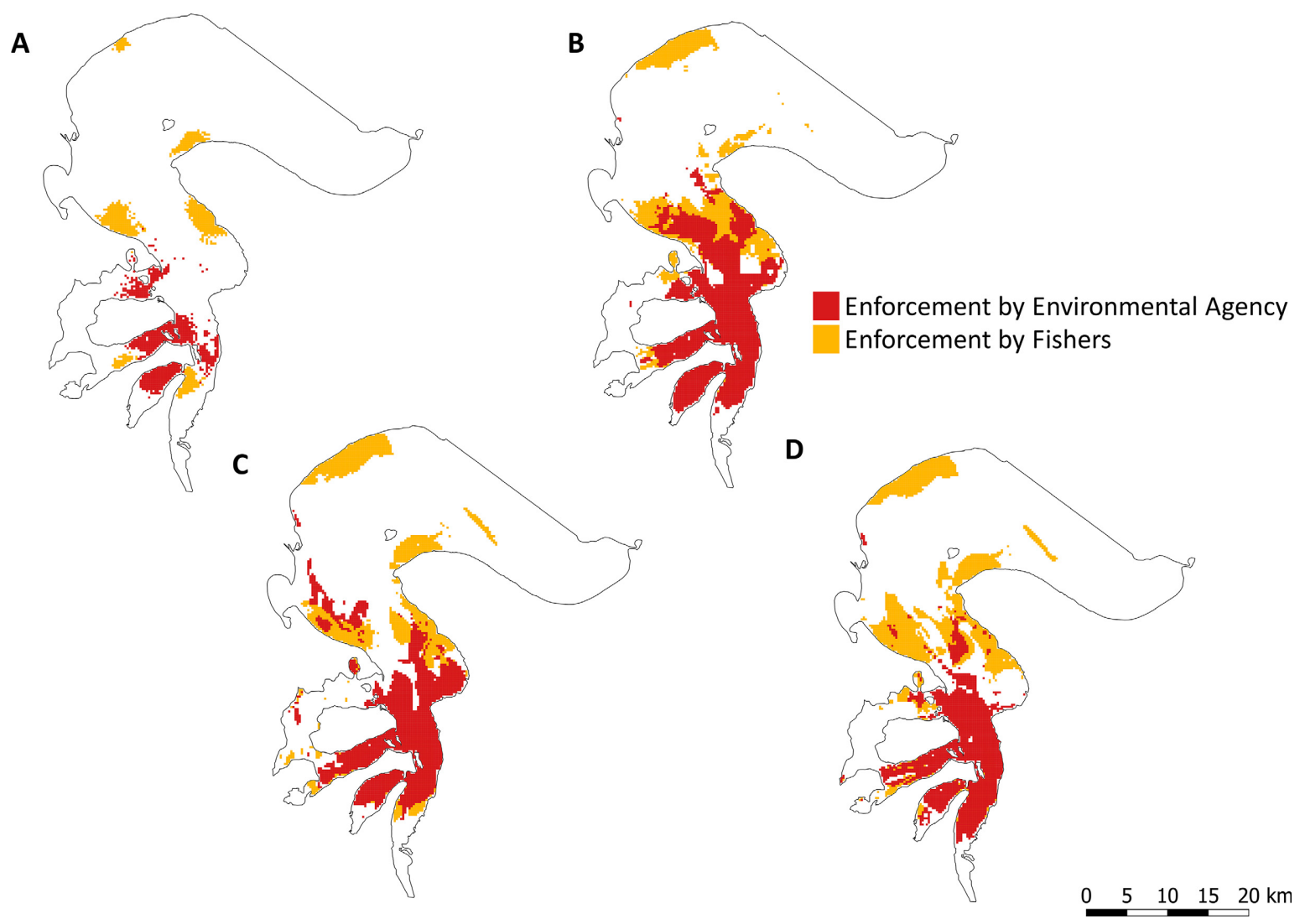

FIG. 4. Co-participative enforcement plan proposed to protect estuarine resources and biodiversity at the Patos Lagoon estuary. This plan is based on the selection frequency results $(\geq 80 \%)$ from scenarios including climate variability as conservation features (Group 3): (A) winter, (B) spring, (C) summer, and (D) autumn). 


\section{ACKNOWLedgements}

This research was funded by the Brazilian National Council for Scientific and Technological Development (CNPq) and supported by the Centre for Biodiversity and Conservation Science (The University of Queensland). We are thankful to our colleagues from the Federal University of Rio Grande for collaborating with our dataset. M. D. de Paula Costa was supported by a CNPq International Postdoctoral Fellowship (234037/2014-8) and J. H. Muelbert by a CNPq Fellowship (310047/2016-1). M. D. de Paula Costa and J. H. Muelbert conceived the study; M. D. de Paula Costa, M. Mills, A. J. Richardson, R. A. Fuller and H. P. Possingham designed the study methodology; M. D. de Paula Costa analysed the data with the input from all other authors; M. D. de Paula Costa led the writing of the manuscript with the contribution from all other authors.

\section{Literature Cited}

Agnew, D. J., J. Pearce, G. Pramod, T. Peatman, R. Watson, J. R. Beddington, and T. J. Pitcher. 2009. Estimating the worldwide extent of illegal fishing. PLoS ONE 4:e4570.

Anderson, L. G. 1989. Enforcement issues in selecting fisheries management policy. Marine Resource Economics 6:261-277.

Arias, A., R. L. Pressey, R. E. Jones, J. G. Alvarez-Romero, and J. E. Cinner. 2016. Optimizing enforcement and compliance in offshore marine protected areas: a case study from Cocos Island, Costa Rica. Oryx 50:18-26.

Arthington, A. H., N. K. Dulvy, W. Gladstone, and I. J. Winfield. 2016. Fish conservation in freshwater and marine realms: status, threats and management. Aquatic Conservation: Marine and Freshwater Ecosystems 26:838-857.

Babler, S. J. M. 2000. Tropical estuarine fishes: ecology, exploitation and conservation. Blackwell Science, Oxford, UK.

Ball, I. R., H. P. Possingham, and M. Watts. 2009. Marxan and relatives: Software for spatial conservation prioritisation. Pages 185-195 in A. Moilanen, K. A. Wilson, and H. P. Possingham, editors. Spatial conservation prioritisation: Quantitative methods and computational tools. Oxford University Press, Oxford, UK.

Ban, N. C., G. J. A. Hansen, M. Jones, and A. C. J. Vincent. 2009. Systematic marine conservation planning in data-poor regions: Socioeconomic data is essential. Marine Policy 33:794-800.

Convention on Biological Diversity. 2013. Quick guide to the Aichi Biodiversity Targets: protected areas increased and improved. www.cbd.int/doc/strategic-plan/targets/T11-quick-guide-en.pdf

Costa, M. D. P., J. H. Muelbert, L. E. Moraes, J. P. Vieira, and J. P. Castello. 2014. Estuarine early life stage habitat occupancy patterns of whitemouth croaker Micropogonias furnieri (Desmarest, 1830) from the Patos Lagoon, Brazil. Fisheries Research 160:77-84.

Costa, M., M. Mills, A. Richardson, R. Fuller, J. Muelbert, and H. Possingham. 2018. Data from: Efficiently enforcing artisanal fisheries to protect estuarine biodiversity. Ecological Applications. https://doi.org/10.14264/uql.2018.266.

Davis, K., M. Kragt, S. Gelcich, S. Schilizzi, and D. Pannell. 2015. Accounting for enforcement costs in the spatial allocation of marine zones. Conservation Biology 29:226-237.

Dhanjal-Adams, K. L., K. Mustin, H. P. Possingham, and R. A. Fuller. 2016. Optimizing disturbance management for wildlife protection: the enforcement allocation problem. Journal of Applied Ecology 53:1214-1215.

Di Franco, A., et al. 2016. Five key attributes can increase marine protected areas performance for small-scale fisheries management. Scientific Reports 6:38135.

D'Incao, F., and E. G. Reis. 2002. Community-based management and technical advice in Patos Lagoon estuary (Brazil). Ocean \& Coastal Management 45:531-539.

Edgar, G. J., et al. 2014. Global conservation outcomes depend on marine protected areas with five key features. Nature 506:216.

Freitas, D. M., and P. R. A. Tagliani. 2009. The use of GIS for the integration of traditional and scientific knowledge in supporting artisanal fisheries management in southern Brazil. Journal of Environmental Management 90:2071-2080.

Game, E. T., M. E. Watts, S. Wooldridge, and H. P. Possingham. 2008. Planning for persistence in marine reserves: a question of catastrophic importance. Ecological Applications 18:670-680.

Game, E. T., H. S. Grantham, A. J. Hobday, R. L. Pressey, A. T. Lombard, L. E. Beckley, K. Gjerde, R. Bustamante, H. P. Possingham, and A. J. Richardson. 2009. Pelagic protected areas: the missing dimension in ocean conservation. Trends in Ecology \& Evolution 24:360-369.

Garcia, A. M., and J. P. Vieira. 1997. Abundância e diversidade da assembleia de peixes dentro e fora de uma pradaria de Ruppia marítima L., no estuário da Lagoa dos Patos, RS-Brasil. Atlântica 19:161-181.

Gelcich, S., M. J. Kaiser, J. C. Castilla, and G. Edwards-Jones. 2008. Engagement in co-management of marine benthic resources influences environmental perceptions of artisanal fishers. Environmental Conservation 35:36-45.

Haimovici, M. 1997. Recursos Pesqueiros Demersais da Região Sul. Avaliação do Potencial Sustentável de Recursos Vivos da Zona Econômica Exclusiva (Revizee). Fundação de Estudos do Mar, Rio de Janeiro, Brazil.

Haimovici, M., and L. G. Cardoso. 2016. Long-term changes in the fisheries in the Patos Lagoon estuary and adjacent coastal waters in Southern Brazil. Marine Biology Research 13:135-150.

Kalikoski, D. C., and T. Satterfield. 2004. On crafting a fisheries comanagement arrangement in the estuary of Patos Lagoon (Brazil): opportunities and challenges faced through implementation. Marine Policy 28:503-522.

Kaliloski, D. C., and M. Vasconcellos. 2012. Case study of the technical, socio-economic and environmental conditions of small-scale fisheries in the estuary of Patos Lagoon, Brazil: a methodology for assessment. FAO Fisheries and Aquaculture Circular. No. 1075. FAO, Rome, Italy.

Kukkala, A. S., and A. Moilanen. 2013. Core concepts of spatial prioritisation in systematic conservation planning. Biological Reviews 88:443-464.

Kurien, J., and R. Willmann. 2009. Special considerations for smallscale fisheries management in developing countries. Pages 404-421 in K. L. Cochrane and M. S. Garcia, editors. A Fishery Manager's Guidebook. FAO, Singapore, Singapore.

MTFCGU. 2016. Portal Transparência-Governo Federal do Brasil. http://www.portaltransparencia.gov.br/

Nhancale, B. A., and R. J. Smith. 2011. The influence of planning unit characteristics on the efficiency and spatial pattern of systematic conservation planning assessments. Biodiversity and Conservation 20:1821-1835.

Odebrecht, C., P. C. Abreu, C. E. Bemvenuti, M. Copertino, J. H. Muelbert, J. P. Vieira, and U. Seeliger. 2010. The Patos Lagoon estuary, Southern Brazil: Biotic responses to natural and anthropogenic impacts in the last decades (1979-2008). Pages 433-455 in M. J. Kennish and P. W. Paerl, editors. Coastal lagoons: critical habitats of environmental change. CRC Press, Boca Raton, Florida, USA.

PBMC. 2014. Base científica das mudanças climáticas. Pages 464 in T. Ambrizzi, and M. Araujo, editors. Contribuição do Grupo de Trabalho 1 do Painel Brasileiro de Mudanças Climáticas ao Primeiro Relatório da Avaliação Nacional sobre Mudanças Climáticas. COPPE. Universidade Federal do Rio de Janeiro, Rio de Janeiro, RJ, Brasil.

Phillips, S. J., and M. Dudik. 2008. Modeling of species distribution with Maxent: new extensions and a comprehensive evaluation. Ecography 31:161-175.

Plumptre, A. J., R. A. Fuller, A. Rwetsiba, F. Wanyama, D. Kujirakwinja, M. Driciru, G. Nangendo, J. E. M. Watson, and H. P. Possingham. 2014. Efficiently targeting resources to deter illegal activities in protected areas. Journal of Applied Ecology 51:714-725.

Pomeroy, R. S., and F. Berkes. 1997. Two to tango: The role of government in fisheries co-management. Marine Policy 21:465-480.

Reis, E. G., and F. D'Incao. 2000. The present status of artisanal fisheries of extreme Southern Brazil: an effort towards 
community-based management. Ocean \& Coastal Management 43:585-595.

Reis, E. G., and H. Rodrigues. 2003. Role of the forum of Patos Lagoon in the management of artisanal fisheries in the extreme south of Brazil. American Fisheries Society Symposium 38:695-701.

Ruas, V. M., M. A. Rodrigues, L. F. C. Dumont, and F. D'Incao. 2014. Habitat selection of the pink shrimp Farfantepenaeus paulensis and the blue crab Callinectes sapidus in an estuary in southern Brazil: influence of salinity and submerged seagrass meadows. Nauplius 22:113-125.
Sumaila, U. R., W. W. L. Cheung, V. W. Y. Lam, D. Pauly, and S. Herrick. 2011. Climate change impacts on the biophysics and economics of world fisheries. Nature Climate Change 1: 449-456.

Vasconcellos, M., A. C. S. Diegues, and R. R. Sales. 2007. Relatório Integrado: Diagnóstico da pesca artesanal no Brasil como subsídio para o fortalecimento institucional da Secretaria Especial de Aquicultura e Pesca. SEAP, Brasília, Brazil.

Vieira, J. P., M. C. Vasconcellos, R. E. Silva, and L. C. Fisher. 1996. A rejeição da pesca camarão-rosa (Penaeus paulensis) no estuário da Lagoa dos Patos, RS, Brasil. Atlântica 18:123-142.

\section{SUPPORTING INFORMATION}

Additional supporting information may be found online at: http://onlinelibrary.wiley.com/doi/10.1002/eap.1744/full

Data Availability

Data available from the University of Queensland eSpace: https://doi.org/10.14264/uq1.2018.266 